Methods 612 mothers were recruited to participate in this cross sectional study from 11 community general paediatric practices. Social capital was assessed using the Social Capital Scale (SCS) and mothers' depressive symptoms were assessed using the Centre for Epidemiologic Depression Scale (CESD). The SCS has five factors. The local IRB approved this study.

Results About 3/4 of mothers were married or had a live in partner, $2 / 3$ were white, median family income was $\$ 30,000$, mothers' average years of school was 13 years. The total SCS score and scores for each of the five factors were all significantly inversely correlated (Spearman) with total score and the CESD ( $\mathrm{p}=$ 0.0001). Total CESD and total SCS $(r=-0.275)$. Belonging to the community factor was slightly stronger $(r=-302)$ than total SCS. While statistically significant, the remaining four factors all had correlations with the total CESD of around -0.2 or less.

Conclusions This study found that, beyond mothers' personal social network, a sense of belonging to the community is an important factor associated with mothers' depressive symptoms. Future studies should include longitudinal assessments of social capital and depressive symptoms to understand better the relation among personal social support, community social capital and depressive symptoms over time.

\section{PS-343 THE RELATIONSHIP BETWEEN PROLONGED QTC INTERVALS AND ANTIPSYCHOTIC DRUGS IN CHILDREN AND ADOLESCENTS: A RETROSPECTIVE CHART REVIEW}

${ }^{1} \mathrm{R}$ Kuge, ${ }^{2} \mathrm{~K}$ Miyazaki, ${ }^{3} \mathrm{M}$ Sakata, ${ }^{1} \mathrm{Y}$ Kikuchi, ${ }^{4} \mathrm{Y}$ Morikawa, ${ }^{2} \mathrm{~T}$ Ookura, ${ }^{2} \mathrm{~N}$ Kondo, ${ }^{5} \mathrm{M}$ Miura. 'Division of Psychology and Welfare, Tokyo Metropolitan Children's Medical Center, Tokyo, Japan; ${ }^{2}$ Division of Child and Adolescent Psychiatry, Tokyo Metropolitan Children's Medical Center, Tokyo, Japan; ${ }^{3}$ Division of Nursing, Tokyo Metropolitan Children's Medical Center, Tokyo, Japan; ${ }^{4}$ Division of Clinical Investigation, Tokyo Metropolitan Children's Medical Center, Tokyo, Japan; ${ }^{5}$ Division of Cardiology, Tokyo Metropolitan Children's Medical Center, Tokyo, Japan

10.1136/archdischild-2014-307384.642

Background Several psychotropic drugs are associated with the prolonged corrected QT interval (QTc) as measured on the electrocardiogram (ECG) that can lead to Torsades de Pointes (TdP) and sudden cardiac death. However, only few studies have evaluated the relationship between prolonged QTc intervals and administration of psychotropic drugs in children and adolescents. Therefore, the objectives of this study were to study the frequency of prolonged QTc intervals and to assess whether there exists a relationship between prolonged QTc intervals and the dose of antipsychotic drugs administered to adolescent psychiatric inpatients.

Methods The study subjects comprised 59 children and adolescents (15 male, 44 female) who were inpatients diagnosed as having F2 according to ICD-10 Classification of Mental and Behavioural Disorders at admission between April 2012 and March 2013. The average age of the subjects was $15.2 \pm 2.0$ years (range: 10.5-18.5 years). We retrospectively reviewed their medical records to characterise patient demographics, medication received, and QTc intervals on the ECG.

Results The average QTc interval recorded was $434.5 \pm 20.3$ msec (range: $391-487$ ). The QTc duration was $\geq 440 \mathrm{msec}$ (range: 442-487) for 21 patients (35.6\%). Chlorpromazine equivalents were similar between patients with normal and prolonged QTc values $(353.9 \pm 301.3$ vs. $420.6 \pm 348.8 ; \mathrm{p}=0.47)$. There were no patients with sudden death or syncope related to TdP.

Conclusions In this study, the frequency of prolonged QTc interval on admission was higher than that previously reported
$(1.97 \%)$, and it did not correlate with the current chlorpromazine equivalents. In the future, we intend to examine the frequency of prolonged QTc intervals among various psychiatric disorders.

\section{PS-344 EFFECTIVENESS OF PROGRAM "5 STEPS FOR HEALTH" IN SCHOLAR CHILDREN IN MEXICO"}

${ }^{1} \mathrm{M}$ Macias, ${ }^{1} \mathrm{C}$ Avila-Huerta, ${ }^{2} \mathrm{~J}$ De la Roca-Chiapas, ${ }^{1} \mathrm{M}$ Garay-Sevilla. ${ }^{1} \mathrm{C}$ iencias Medicas, Universidad de Guanajuato, Leon, Mexico; ${ }^{2}$ Psicologia, Universidad de Guanajuato, Leon, Mexico

\subsection{6/archdischild-2014-307384.643}

Background Obesity and sedentary lifestyle has increased in the last years. In Mexico, The Ministry of Education included information for children about physical activity and nutrition in elementary schools, in another hand, The Health Ministry suggest the program ' 5 steps for health' $(5 \mathrm{SH})$, which is based in theory to change habits.

Aim Investigate the change to healthy habits in children 10 to 12 years old comparing traditional education Vs ' $5 \mathrm{SH}$ '

Methods Children were randomly assigned to traditional education group ( $\mathrm{n}=101,1$ session/week) or $5 \mathrm{SH}$ group $(\mathrm{n}=134,2$ sessions/week) and followed for 6 months; and six months later were interviewed to verify the change of habits. At the beginning and the end of study physical activity was recorder by survey, weight and height were measured and classified as normal, overweight or obese according Body Mass Index (BMI).

Results At beginning of study both groups were similar, and one year of follow-up we found more overweight and obese in the children with traditional education vs $5 \mathrm{SH} 34.7 \%$ and $5.9 \%$ vs $17.2 \%$ and $3.0 \%$, respectively $\left(X^{2}=11.2 ; \mathrm{p}=0.003\right)$. Physical activity increased in $5 \mathrm{SH}$ group from $124 \pm 124 \mathrm{~min} /$ week to $232 \pm 113 \mathrm{~min} / \mathrm{week} ;(\mathrm{p}<0.001)$ than traditional group from $131 \pm 128 \mathrm{~min} /$ week to $177 \pm 130 \mathrm{~min} /$ week; $(\mathrm{p}>0.05)$.

Conclusions The program ' 5 steps for health' focused in change of habits is more effective than traditional education to increase physical activity and prevent obesity.

\section{PS-345 REDUCTION OF PAEDIATRIC EMERGENCY HOSPITAL ADMISSIONS BY MODIFICATIONS IN PAEDIATRIC EMERGENCY DEPARTMENT POLICY}

A Elhassanien. Pediatrics, Mansoura Faculty of Medicine, Mansoura, Egypt

\subsection{6/archdischild-2014-307384.644}

Background Reduction in admissions is an important aim of emergency department working policy to overcome the problems of a shortage of inpatient beds, rising costs and exhausted resources. A new policy was instituted in the paediatric emergency department (PED) of a hospital in Kuwait with the following components: (1) assigning senior doctor staff (2) implementation of new disease management guidelines; and (3) maximising the useof the paediatric emergency department observation unit.

Objective To evaluate the effect of change in our policy on the admission rate.

Methods The effects of this policy on reduction of admission rates for total paediatric admissions and for some selected common paediatric conditions were prospectively studied over a period of 3 years from institution of the policy and compared with the 3-year period before the policy was instituted. 
Results There was a significant reduction in admission rates after institution of the new policy. The proportion of hospital admissions to PED observation unit cases was significantly reduced as a whole from $64.9 \% \pm 5.1 \%$ to $33.2 \pm 0.6 \%$ and also for the common paediatric problems studied.

Conclusion A multidisciplinary paediatric emergency department policy, using as much available evidence as possible, was successful in significantly reducing paediatric hospital admissions.

\section{PS-346 IMPROVING THE STANDARD OF INVASIVE PROCEDURES IN PAEDIATRICS - A TEACHING INTERVENTION TO ALIGN CURRENT PRACTICE TO BRITISH PSYCHOLOGICAL SOCIETY GUIDELINES}

M Monaghan, J Criddle, A Osborn. Paediatric Emergency Department, Evelina London Children's Hospital, London, UK

\subsection{6/archdischild-2014-307384.645}

Background/aims Invasive procedures (eg intravenous cannulation) remain a leading cause of distress in children. They are performed daily yet rarely taught formally, leading to variation in practice. The British Psychological Society (BPS) created guidelines in 2010, although these have yet to be implemented in a formal teaching programme. Our teaching intervention aimed to align practice to BPS guidelines and improve professional confidence.

Methods Teaching sessions were delivered to professionals involved in cannulation at two South London hospitals by a senior play specialist and a paediatrician. Sessions covered assessment, preparation, teamwork, implementation and post-procedural care. A poster containing a flowchart was used for teaching and departmental reference.

Results Thirteen professionals involved in cannulation $(9$ medical, 4 nursing) reported their previous teaching experiences. 5 reported never receiving training in paediatric invasive procedures, 6 informal teaching and only 2 receiving formal teaching (1 medical, 1 nursing). Pre-intervention confidence was 5.7/10 $(n=13)$ [range 0-8]. This improved to 7.3/10 [range 4-9] post intervention. The intervention usefulness was rated $8.3 / 10(\mathrm{n}=$ 12 , range 5-10]. When self-reporting practical considerations for cannulation, 8/12 mentioned local anaesthetic creams but only 6/ 12 mentioned using distraction or a play specialist.

Conclusions This intervention aimed to address the lack of formal teaching available in Paediatric invasive procedures. It highlighted areas of BPS guidance that remain underappreciated despite their greater efficacy (eg the importance of distraction vs anaesthetic cream). Initial levels of confidence showed improvement post-intervention. We recommend this teaching intervention to be used regularly throughout Paediatric departments and undergraduate medical programmes.

\section{PS-347 HEALTH-RELATED QUALITY OF LIFE OF PORTUGUESE CHILDREN AND ADOLESCENTS IN PRIMARY CARE: REGIONAL CHARACTERISTICS AND COMPARISON TO EUROPEAN DATA}

${ }^{1}$ I Marques, ${ }^{2} \mathrm{M}$ Abreu, ${ }^{1} \mathrm{C}$ Prelhaz, ${ }^{2} \mathrm{M}$ Martins, ${ }^{1} \mathrm{AG}$ Silva, ${ }^{3} \mathrm{TM}$ Fernandes, ${ }^{4} \mathrm{R}$ Ascenção, ${ }^{3} \mathrm{P}$ Gomes. ${ }^{1}$ Paediatrics, Centro Hospitalar Barreiro-Montijo, Barreiro, Portugal; ${ }^{2}$ Paediatrics, Hospital Pedro Hispano, Matosinhos, Portugal; ${ }^{3}$ Family Medicine, Unidade Saúde Familiar Infesta, Matosinhos, Portugal; ${ }^{4}$ Family Medicine, Unidade Cuidados Saúde Personalizados Sete Rios, Lisboa, Portugal
Background Children and adolescent health has been recognised as an important indicator of a country's development and global health. Adopting a health-related quality of life (HRQoL) approach can not only increase understanding of their own health but also help to establish policies that promote their safety and wellbeing.

Aims Evaluate HRQoL in a sample of Portuguese children and adolescents at primary care level, and assess age, gender and regional differences. Compare these results with the available European data.

Methods Cross-sectional observational study. Participants included 163 children and adolescents aged 8-18 years, presenting to a regular follow-up consultation at two primary care services (Lisbon and Oporto), during a six months period between 2012/13. HRQoL was assessed using KIDSCREEN-27, a selfreport questionnaire that consists of five dimensions: Physical Wellbeing, Psychological Wellbeing, Autonomy and Parent Relations, Social Support and Peers, and School Environment. Statistics were calculated using SPSS Statistics 20.0.

Results The HRQoL scores, in all five dimensions, were consistently lower in female gender, adolescents and patients from Oporto region. However, statistically significant differences were found only for gender and age at the physical wellbeing dimension ( $p=0.001$ and $p=0.02$, respectively). Compared to the European data our patients presented significantly higher HRQoL scores in all five dimensions ( $\mathrm{p}=0.025)$.

Conclusions The results underline the fact that females and adolescents should be the main targets when planning successful health policies and practices. Also, they call the attention for loco-regional differences that must be taken into account. Despite our patients presenting higher HRQoL scores, the results are according to the literature.

\section{PS-348 CHILDREN'S CLINICAL PROFILE: TERTIARY PAEDIATRIC BALANCE CLINIC}

${ }^{1}$ A Shetye, ${ }^{2}$ E Raglan. 'Department of Audiological Medicine, East and North Herts NHS Trust, Stevenage, UK; ${ }^{2}$ Department of Audiological Medicine, Great Ormond Street Hospital NHS Foundation Trust, London, UK

\subsection{6/archdischild-2014-307384.647}

Main purpose The main aim was to analyse the clinical profile of children with and without hearing impairment referred with various vestibular related symptoms attending a tertiary balance clinic over six months. Children undergoing pre-cochlear implant assessment were also included.

Design of study A thorough clinical history and evaluation of auditory and vestibular assessment was undertaken. Diagnosis of the medical condition was made on the basis of all the above.

Results One hundred and twenty four consecutive patients (55 female and 69 male) were included. The age range was 9 months to 18.5 years (mean age 9.41 years). Multiple professionals referred these patients.

Associated conditions: Ten patients had a history of migraine, 8 had cyclical vomiting, 8 had CHARGE syndrome, 7 referred post-meningitis had labyrinthitis ossificans. Three patients sustained head injury.

Signs:- Two patients had positional nystagmus: one with history of head injury, the other sustained vibration injury to the labyrinth caused during fairground rides. Head impulse test was positive bilaterally in seventeen patients, indicated by the presence of catch-up saccade, a clinical feature of vestibular failure. 